\title{
Role of $\alpha 7$ nicotinic receptor in the immune system and intracellular signaling pathways
}

\author{
ROBERT ZDANOWSKI', MAEGORZATA KRZYŻOWSKA', DOMINIKA UJAZDOWSKA ${ }^{2}$, \\ ANETA LEWICKA ${ }^{3}$, SŁAWOMIR LEWICKI ${ }^{I}$
}

\author{
${ }^{1}$ Department of Regenerative Medicine, Military Institute of Hygiene and Epidemiology, Warsaw, Poland \\ ${ }^{2}$ Research and Development Division, Adamed Sp. z o.o., Czosnów, Poland \\ ${ }^{3}$ Department of Hygiene and Physiology, Military Institute of Hygiene and Epidemiology, Warsaw, Poland
}

\begin{abstract}
Acetylcholine has been well known as one of the most exemplary neurotransmitters. In humans, this versatile molecule and its synthesizing enzyme, choline acetyltransferase, have been found in various non-neural tissues such as the epithelium, endothelium, mesothelium muscle, blood cells and immune cells. The non-neuronal acetylcholine is accompanied by the expression of acetylcholinesterase and nicotinic/muscarinic acetylcholine receptors. Increasing evidence of the non-neuronal acetylcholine system found throughout the last few years has indicated this neurotransmitter as one of the major cellular signaling molecules (associated e.g. with kinases and transcription factors activity). This system is responsible for maintenance and optimization of the cellular function, such as proliferation, differentiation, adhesion, migration, intercellular contact and apoptosis. Additionally, it controls proper activity of immune cells and affects differentiation, antigen presentation or cytokine production (both pro- and anti-inflammatory). The present article reviews recent findings about the non-neuronal cholinergic system in the field of immune system and intracellular signaling pathways.
\end{abstract}

Key words: $\alpha 7$ nicotinic receptor, immune system, intracellular signaling pathways.

(Cent Eur J Immunol 2015; 40 (3): 373-379)

\section{Introduction}

Acetylcholine (ACh) was the first characterized neurotransmitter [1]. It is an organic molecule and one of many neurotransmitters in the autonomic nervous system (ANS). There are two main classes of acetylcholine receptors (AChR): nicotinic acetylcholine receptors (nA$\mathrm{ChR}$ ) and muscarinic acetylcholine receptors (mAChR). The $\mathrm{nAChR}$ is the best-characterized ligand-dependent, cation-selective channel receptor. Nicotinic acetylcholine receptors are present in the autonomic ganglia and at the neuromuscular junction. In the brain, nAChRs play an important role in the brain activity modulating synaptic and cellular functions [2], while in muscles they are involved in neural activation of muscle spasms [3]. In vertebrate species, 17 different subunits of nAChR have been identified $(\alpha 1-10, \beta 1-4, \delta, \varepsilon, \gamma)[4]$. The subunits form a large number of homo-and heteropentameric receptors and all these combinations show specific pharmacological properties. Stimulation of nAChRs opens channels, induces an inflow of sodium ions and/or calcium ions as well as a potassium ions outflow (Fig. 1). As a result of membrane depolarization, voltage-operated calcium channels are opened, leading to an additional flow of calcium ions. The influx of calcium causes secretion of mitogenic factors and activates cell signaling cascades [5].

The terms 'non-neuronal cholinergic system' and 'non-neuronal acetylcholine' were first introduced in the 1970s by Sastry and Sadavongvivad [6]. Since that time, multiple studies have been performed to investigate the function of $\mathrm{nACh}$ receptors in different non-neuronal tissues. Nicotinic acetylcholine receptors were found on keratinocytes [7], blood cells including lymphocytes, macrophages, mast cells, dendritic cells, basophils [8], microglia, endothelial cells [9], epithelial cells and fibroblasts [10, 11]. The expression of this receptor was also observed in tumor cells, suggesting its potential role in cancer progression [12]. Modulation of nAChRs activity in cells from 'non-neuronal cholinergic system' was associated with changes in proliferation, differentiation, migration, adhesion, cell contact, apoptosis, and angiogenesis process $[7,13,14]$. The expression of nAChRs was also detected in spermatogonia, spermatocytes, seminiferous tubular and Sertoli cells. This suggests that the presence of the non-neuronal cholinergic system in testicular parenchyma

Correspondence: Małgorzata Krzyżowska, Department of Regenerative Medicine, Military Institute of Hygiene and Epidemiology, ul. Kozielska 4, 01-163 Warsaw, Poland, e-mail: krzyzowskam@yahoo.com 
Five $\alpha 7$ subunits form an $\alpha 7$ homo-oligomeric nAChR

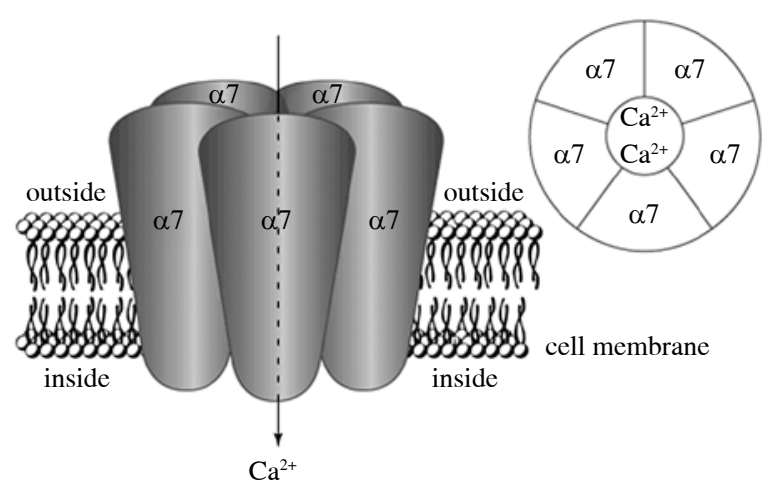

Two $\alpha 4$ and three $\beta 2$ subunits an $\alpha 4 \beta 2$ heteromeric nAChR

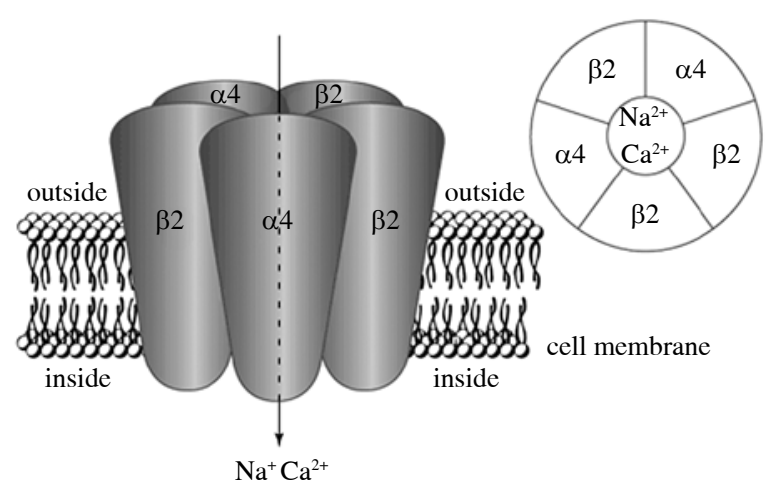

Fig. 1. Schematic representation of the two most common subtypes of nAChRs. Both receptors consist of five subunits. The $\alpha 7$ nicotinic acetylcholine receptor (nAChR) consists of five $\alpha 7$ subunits and is called $\alpha 7$ homo-oligomeric $\mathrm{nAChR}$ (left). The $\alpha 4 \beta 2 \mathrm{nAChR}$ is composed of two $\alpha 4$ subunits and three $\beta 2$ subunits and thus is called $\alpha 4 \beta 2$ heteromeric nAChR (right). In both nAChRs, subunits are arranged around a central pore or channel that opens when agents such as acetylcholine or nicotine bind to an $\mathrm{nAChR}$, allowing positively charged ions to flow through the channel into the cell. The $\alpha 7 \mathrm{nAChR}$ principally allows passage of calcium $\left(\mathrm{Ca}^{2+}\right)$ ions, whereas the $\alpha 4 \beta 2 \mathrm{nAChR}$ allows passage of both calcium and sodium $\left(\mathrm{Na}^{+}\right)[16]$

plays a potentially important role in the differentiation of germ cells [15].

\section{The role of the non-neuronal cholinergic system in the immune system}

Studies performed in the past years have indicated that cholinergic transmission may modulate various aspects of both innate and adaptive immune response. It has been shown that acetylcholine - an element of the non-neuronal cholinergic system - exhibits an anti-inflammatory action. Acetylcholine may affect the immune system in two different ways - autocrine/paracrine (immune cells have the capacity of acetylcholine secretion) or nerve stimulation $[17,18]$.

'Cholinergic anti-inflammatory pathway' response plays a role in the immune response and inflammatory cascade. The non-neuronal cholinergic system affects also immune cell proliferation, T helper differentiation, antigen presentation and cytokine production. The $\alpha-7$ nicotinic acetylcholine receptor ( $\alpha 7-\mathrm{nAChR})$, a part of the non-neuronal cholinergic system, plays a specific role in the immune response. It is localized in various immune cells, i.e. macrophages, dendritic cells, $\mathrm{T}$ and $\mathrm{B}$ lymphocytes, mast cells, or basophils [14, 19-21].

The cytokine suppressing mechanism of the inflammatory reflex - "cholinergic anti-inflammatory pathway" - requires the $\alpha-7$ subunit of nicotinic acetylcholine receptor ( $\alpha 7-\mathrm{nAChR})$. As already known, stimulation of the vagal nerve protects from excessive cytokine production. The release of acetylcholine in spleen suppresses production of pro-inflammatory cytokines (e.g. TNF- $\alpha$ ) and attenuates inflammation [22]. Signaling through the efferent arc of the inflammatory reflex regulates the innate immune response [23]. Interestingly, Olofsson et al. [24] have demonstrated that deficiency of $\alpha 7$-nAChRs in the bone marrow cells significantly impaired nerve regulation of TNF release, but $\alpha 7-n A C h R$ deficiency in neurons, or other cells had no significant effect. Authors suggested that the expression of $\alpha 7-n A C h R$ on most of the immune cells, but not in the neurons or T cells, is necessary to sustain the inflammatory reflex function. Furthermore, deficiency or impairment of $\alpha 7-\mathrm{nAChR}$ signaling leads to overproduction of cytokines, and enhances tissue damage [25]. Positive agonists of $\alpha 7-n A C h R$ were used in preventing tissue damage caused by the inflammatory process. Sun $e t$ al. [26] have shown that administration of PNU-120596, a type-II positive allosteric modulator (PAM-II) of $\alpha 7$ nicotinic acetylcholine receptors, reduces brain injury and improves the neurological function after focal cerebral ischemia in rats. Additionally, PNU-120596 administration had anti-nociceptive effects in mice models of persistent pain [27].

The $\alpha-7$ nicotinic acetylcholine receptor is necessary for regulation of macrophage cytokine release. Macrophages isolated from the wild type mouse produced significantly lower levels of tumor necrosis factor $\alpha$ (TNF- $\alpha$ ) after LPS stimulation if 5-10 minutes before they were pre-incubated with nicotine $(1,10 \mu \mathrm{M})$ or acetylcholine $(10 \mu \mathrm{M})$ than macrophages isolated from $\alpha 7-n A C h R$ knockout mice [28]. In LPS-stimulated human macrophage cultures, acetylcholine attenuated release of cytokines: (TNF- $\alpha$ ), IL-1 $\beta$, IL-6 and IL-18, but not the anti-inflammatory cytokine IL-10 [29]. Similarly, Rosas-Ballina 
et al. [30] have shown that an $\alpha 7-n A c h R$ agonist (GTS-21) suppresses pro-inflammatory cytokine production (mainly TNF- $\alpha$ and IL-1 $\beta$ ) in response to various toll-like receptor (TLR) ligands e.g. TLR2, TLR3, and TLR9 agonists. This relationship was also observed in culture of microglia cells where acetylcholine and nicotine pre-treatment inhibited lipopolysaccharide (LPS)-induced TNF- $\alpha$ release [31].

$\mathrm{T}$ cells possess all cholinergic elements of the non-neuronal cholinergic system: acetylcholine, choline acetyltransferase (ChAT), muscarinic and nicotinic acetylcholine receptors and acetylcholinesterase. B cells possess muscarinic and nicotinic acetylcholine receptors and acetylcholinesterase. ACh or nicotine treatment of T and B cells causes rapid and transient intercellular calcium ion signaling in these cells. Rosas-Bollina et al. [23] demonstrated the role of the vagus nerve and ACh in controlling the innate immune response (reduction of inflammation). The vagus nerve stimulated acetylcholine-producing memory phenotype $\mathrm{T}$ cells, which were required for inhibition of cytokine production. Permanent nicotine stimulation down-regulates the $\mathrm{nAChR}$ expression and suppresses T cell activity [32-34]. Moreover, Fujii et al. [35] showed that stimulation of the $\mathrm{T}$ cell receptor (TCR) using a $\mathrm{T}$ cell activator - phytohemagglutinin (PHA), induces ACh synthesis and release in MOLT-3 and HSB-2 cells (human leukemic $\mathrm{T}$ cell lines). It is well known that antagonists of the $\alpha 7$-nAChR, such as $\alpha$-bungarotoxin ( $\alpha$-BTX) and methyllycaconitine (MLA), enhance T cell proliferation. Recent data indicate that $\alpha 7-\mathrm{nAChR}$ seems to be a key regulator of immunosuppressive functions of $\mathrm{CD} 44^{+} \mathrm{CD} 25^{+}$ regulatory T cells [36]. Additionally, Nordman et al. [37] revealed that not only $\alpha 7-n A C h R s$ but also $\alpha 4-n A C h R$ nicotinic receptors are involved in $\mathrm{CD} 4^{+} \mathrm{T}$-cell proliferation and helper $\mathrm{T}$-cell immune response.

Activation of $\alpha 7-n A C h R s$ affect dendritic and mast cells metabolism. Studies performed in vitro in human dendritic cells after nicotine administration showed a decrease in their phagocytic activity and secretion of pro-inflammatory cytokines [38]. Nicotine inhibits IL-12 release by LPS-matured human competent dendritic cells and reduces secretion of IFN- $\gamma$ by the primed T cells [39]. Simultaneously, nicotine administered to mice stimulated with prophylactic and therapeutic vaccines, adversely affects dendritic cells and prevents development and maintaining of Ag-specific effector memory Th1 cells and Ab production [40]. Studies performed on rats revealed that acetylcholine, choline and nicotine induce mast cell degranulation [41]. Mishra et al. [42] have demonstrated that nicotine affects the late, but not the early, degranulation phase of the mast cell activation. Authors suggested that nAChRs localized on mast cells might be an important component for new therapeutic approaches to control allergic diseases and allergic asthma. The $\alpha 7$-nAChR specific agonist GTS21 also shows anti-inflammatory effects on mucosal-type murine bone marrow-derived mast cells (mBMMCs) and inhibits IgE-induced degranulation [43].

Nicotinic acetylcholine receptor also regulates the expression of cell surface proteins associated with regulation of leukocyte trafficking to peripheral inflammatory sites. CD11b on the surface of neutrophils is necessary for $\beta 2$-integrin regulated neutrophil adhesion to the endothelium and neutrophil transmigration to sites of microbial infection [9]. It has been shown that nicotine administration and vagus nerve stimulation (VNS) significantly reduced both LPS- and fMLP-(N-formyl-methionyl-leucyl-phenylalanine) induced neutrophil surface CD11b expression via suppression of F-actin polymerization [44].

The ACh esterase plays an important role in the acetylcholine stimulation of non-neural immune cells. The enzyme is a member of the $\alpha / \beta$ hydrolase family and it degrades the excitatory neurotransmitter acetylcholine (ACh). Degradation of ACh by acetylcholinesterase (AChE) is necessary for termination of the signal and may be controlled at different cell levels. AChE can be incorrectly translocated from the cytoplasm to the membrane, which was observed in an autoimmune disease - myasthenia gravis [45]. Acetylcholinesterase function can be also modulated by an increase or decrease in its activity. Gilboa-Geffen et al. [46] in non-obese diabetic mice showed that TLR9 activated by oligonucleotide BL-7040 induced an alternative NF- $\mathrm{B}$ activation mode resulting in a reduced peripheral AChE activity. Similarly, Ofek et al. [47] observed in young volunteers an increase or decrease in the plasma AChE activity $1.5 \mathrm{~h}$ after Escherichia coli endotoxin administration compared to saline. Moreover, $\mathrm{AChE}$ function can be regulated at the expression level by alternative splicing [48], microRNA suppression [49] or transcriptional control [50].

\section{$\alpha 7-n A C h R$ and signaling pathways}

The $\alpha 7$-nAChR subtype is activated quickly and its desensitization is fast. This receptor exhibits a higher permeability for calcium ions in relation to other nAChRs [51]. As a result of increased intracellular calcium concentrations, the cellular signaling pathways are activated leading to the inflammatory response or cancer progression [52]. The influx of calcium ions activates phosphorylation cascade via protein kinase C (PKC), serine-threonine kinase Raf-1, mitogen-activated protein kinase (MAPK) [53] and/ or extracellular signal-regulated kinase ERK1, ERK2 [54]. It has been shown that many intracellular proteins interact with $\alpha 7-n A C h R s$ and participate in signal transduction [55]. As a result of nAChRs activation, nuclear transcription factor kappaB $(\mathrm{NF}-\kappa \mathrm{B})$ is activated via the Janus kinase 2 (JAK-2) [56], phosphatidylinositol kinases PI3K and serine-threonine protein kinase AKT [57]. Other transcription factors were also activated by stimulation of $\mathrm{nA}$ ChR: activator protein-1 (AP-1), signal transducer and ac- 
tivator or transcription 1 (STAT1), STAT3 and STAT5 in the JAK-2/PI3K/AKT pathway [52, 59]. The $\alpha 7-n A C h$ receptor is also engaged in Ras-Raf-ERK signaling pathway [60]. Activated nAChRs mediate carcinogenic processes including proliferation, inhibition of apoptosis, angiogenesis, migration and cell adhesion [61]. Antagonists of nAChRs may help to inhibit tumor cell proliferation [62]. Other researchers suggest that molecular therapy strategies aimed at nAChRs inhibition or siRNA silencing in lung cancer may reduce tumor growth and development [12].

Nicotine activation of the $\alpha 7$-nicotinic acetylcholine receptor resulted in activation of $\alpha 7-\mathrm{nAChR}-\mathrm{JAK} 2-$ (NF-кB; STAT3)-Bcl-2 signaling pathway and caused a reduction in the apoptosis process [56]. De Jonge et al. [58] revealed that acetylcholine released by the efferent vagal nerve inhibits macrophage activation. Stimulation of $\alpha 7-n A C h R s$ in mouse macrophages in vitro and in vivo leads to an anti-inflammatory effect via the JAK2STAT3 signaling pathway. In turn, Wang et al. [62] have observed that activation of $\alpha 7 \mathrm{nAChRs}$ on human macrophages inhibits activation of the NF- $\kappa \mathrm{B}$ signaling pathway induced by either endotoxin or TNF- $\alpha$. This caused inhibition of pro-inflammatory cytokines release. Activation of $\alpha 7-n A C h R$, an endogenous inflammation-resolving pathway, prevents TNF- $\alpha$ induced NF- $\kappa$ B activation and inhibits macrophage migration into the hippocampus [63]. A study by Waldburger et al. [64] shows that activation of $\alpha 7-n A C h R s$ by an agonist inhibits cytokine production by resident fibroblast-like synoviocytes (FLS), which are potentially directly involved in propagation of inflammation. In another study, Al-Wadei et al. [65] showed that nicotinic agonists - acetylcholine, nicotine, and its nitrosated carcinogenic derivative NNK activated phosphorylation of CREB (cAMP response element-binding protein), ERK, SRC (proto-oncogene tyrosineprotein kinase) and AKT. Also, nAChRs stimulate growth and migration of pancreatic cancer cells.

Stimulation of $\alpha 7$-nAChRs by nicotine increases the expression of $\beta$-defensins in keratinocytes [66]. Li et al. [67] have shown inhibition of TNF- $\alpha$ expression in response to LPS after an $\alpha 7-\mathrm{nAChR}$ nicotine stimulation. Moreover, nicotine administration decreased the expression of primary response gene 88 protein (MyD88), NF- $\kappa \mathrm{B}$ p65 protein, phospho-I- $\kappa \mathrm{B} \alpha$, TNF- $\alpha$ as well as NF- $\kappa \mathrm{B}$ activity induced by LPS in airway epithelial cells (HBE16). The addition of an $\alpha 7$-nAChR inhibitor $-\alpha$-bungarotoxin caused the opposite effect. Nicotine reduced also TNF- expression through the $\alpha 7 \mathrm{nAChR/MyD88/NF- \kappa B}$ pathway. In addition, Li et al. [67] revealed that when silencing of $\alpha 1, \alpha 5$ or $\alpha 7-n A C h R s$ in airway epithelial cells (HBE16) with appropriate siRNA, only the $\alpha 7-n A C h R$ is responsible for lowering TNF- $\alpha$ production.

In normal human bronchial epithelial (HBE) cells, nicotine administration resulted in phosphorylation of the signaling protein p38MAPK [68], Akt [69] and an increase in proliferation of small cell lung cancer cell lines [70]. It is well known that Akt participates in cellular processes such as, glucose metabolism, cell cycle progression, and apoptosis [71]. Nicotine has been reported to inactivate the pro-apoptotic protein Bax [72], also by the Akt signaling pathway. In HEK $273 \mathrm{~T}$ cells, the influx of calcium stimulated by nicotine can be blocked by $\alpha$-BTX (an antagonist of $\alpha 7-n A C h R)$. Activation of Akt increased phosphorylation of downstream substrates including GSK-3, p70S6K, 4EBP-1, and FKHR and could contribute to tumorigenesis in vivo in lymphoid, breast, ovarian, prostate, and brain tissues [73]. Other study showed that in neuronal cells, $\alpha 7-n A C h R$ activates the PI3K/Akt pathway by activation of a Src family member [74].

Nicotine at a concentration of $10 \mathrm{mM}$ caused phosphorylation of mitogen-activated protein kinase $\mathrm{p}$ 44/42 MAPK in non-small cell lung cancer (NSCLC) cell lines. p44/42 MAPK is often up-regulated in cancer and can be inhibited using nAChR antagonists. Moreover, nicotine can activate $\alpha 7$-nAChRs to inhibit the expression of inducible nitric oxide synthase and nitric oxide through the mitogen-activated protein kinase (MAPK)/NF- $\kappa \mathrm{B}$ pathway [75]. Nicotine activation of $\mathrm{nAChR}, \mathrm{NF}-\kappa \mathrm{B}$ p65 and $\mathrm{p} 50$, $\mathrm{I}-\kappa \mathrm{B} \alpha$ activation, and the MAPK signaling pathway induced vascular endothelial cells to produce adhesion molecule: ICAM-1 and VCAM-1 [76].

Cholinergic receptors stimulation via $\mathrm{AAChR}$ agonists, such as nicotine and GTS-21 or the vagus nerve stimulation suppresses leukocyte recruitment and the endothelial cell activation. Chatterjee et al. have shown significantly reduced production of IL-6-mediated monocyte chemoattractant protein-1 (MCP-1) and ICAM-1 expression regulated through the JAK2/STAT3 pathway in macrovascular human umbilical vein endothelial cells (HUVECs) and microvascular endothelial cells (MVECs). Authors found that cells treated with cholinergic agonists (e.g., nicotine and GTS-21) significantly reduced phosphorylation of JAK2, reduced STAT3 activation (by phosphorylation and DNA binding) and decreased levels of SOCS3 (suppressor of cytokine signaling). These changes resulted in suppression of IL-6-mediated endothelial cells activation via the JAK2/ STAT3 pathway [77]. Similarly, Saeed et al. demonstrated that cholinergic agonists (nicotine) suppressed endothelial cell activation (in in vitro and in vivo studies) and leukocyte migration in a carrageenan air pouch model [78]. On the other hand, studies performed by de Jonge et al. [53] showed that nicotine induced STAT3 activation in macrophages following LPS treatment. Also Chen et al. [79] have observed simultaneous activation of Stat 3 and extracellular signal regulated kinase 1/2 (ERK1/2) in T24 cells after nicotine administration. However, long-term nicotine exposure induced activation of Stat 3 and down-regulation of ERK1/2 via nAChR and $\beta$-adrenoceptors in human bladder cancer cells (T24 cell line) [80]. 
Activation of calcium ions transport by $\alpha 7-n$ AChRs plays an important role in the cell survival. Increase in intracellular calcium ions can cause indirect activation of $\beta$-adrenergic receptor signaling, which induces activation of epidermal growth factor (EGF) and activation of epidermal growth factor receptor (EGFR). EGFR activates the Akt pathway and its downstream effectors, X-linked inhibitor of apoptosis protein (XIAP)-survivin and nuclear factor $-\kappa \mathrm{B}(\mathrm{NF}-\kappa \mathrm{B})$. Furthermore, nicotinic stimulation of $\alpha 7-n A C h R s$ confirmed the anti-apoptotic activity of these receptors by activation of PKC, PKA and NF- $\kappa \mathrm{B}$, and down-regulation of the tumor suppressor p53 [81]. NF- $\kappa \mathrm{B}$ phosphorylation caused by nicotine also promotes phosphorylation of the apoptotic protein Bad and Bax and involvement of MEK and PI3K pathways [82].

\section{Summary}

Acetylcholine is produced by practically all types of the living cells. The neurotransmitter participates in numerous interrelated biologic processes such as proliferation, differentiation, apoptosis, adhesion, and migration. Both acetylcholine and nicotine (agonists of nAChR) may affect different kinds of cells by autocrine or paracrine stimulation. The cholinergic anti-inflammatory pathway is an important mechanism that inhibits cytokine production and minimizes tissue injury during inflammation. As known now, the stimulation of the vagus nerve, which releases acetylcholine, and administration of cholinergic agonists, such as nicotine and GTS-21, reduce cytokine production in the models of acute, systemic inflammation, including endotoxemia, hemorrhagic shock, ischemia-reperfusion injury, and polymicrobial sepsis. Proper inhibition or stimulation of this nicotinic acetylcholine receptor (or its selected subtype) may give comprehensive therapeutic possibilities to effective treatment of neurodegenerative as well as inflammatory, autoimmune or cancer diseases. However, for proper application of such therapies $\mathrm{nAChR}$ modulation in different kinds of cells should be fully understood.

\section{The authors declare no conflict of interest.}

\section{References}

1. Loewi O (1921): Über humerole übertragbarkeit der herznervenwirkung. I. Mitteilung. Pflügers Arch Ges Physiol 189: 239-242.

2. Picciotto MR, Higley MJ, Mineur YS (2012): Acetylcholine as a neuromodulator: cholinergic signaling shapes nervous system function and behavior. Neuron 76: 116-129.

3. Fagerlund MJ, Eriksson LI (2009): Current concepts in neuromuscular transmission. Br J Anaesth 103: 108-114.

4. Millar NS (2003): Assembly and subunit diversity of nicotinic acetylcholine receptors. Biochem Soc Trans 31: 869-874.
5. Albuquerque EX, Pereira EF, Alkondon M, et al. (2009): Mammalian nicotinic acetylcholine receptors: from structure to function. Physiol Rev 89: 73-120.

6. Sastry BV, Sadavongvivad C (1978): Cholinergic systems in non-nervous tissues. Pharmacol Rev 30: 65-132.

7. Zia S, Ndoye A, Lee TX, et al. (2000): Receptor-mediated inhibition of keratinocyte migration by nicotine involves modulations of calcium influx and intracellular concentration. J Pharmacol Exp Ther 293: 973-981.

8. Kawashima K, Yoshikawa K, Fujii YX, et al. (2007): Expression and function of genes encoding cholinergic components in murine immune cells. Life Sci 80: 2314-2319.

9. Wang Y, Pereira EF, Maus AD, et al. (2001): Human bronchial epithelial and endothelial cells express $\alpha 7$ nicotinic acetylcholine receptors. Mol Pharmacol 60: 1201-1209.

10. Zia S, Ndoye A, Nguyen VT, et al. (1997): Nicotine enhances expression of the $\alpha 3, \alpha 4, \alpha 5$ and $\alpha 7$ nicotinic receptors modulating calcium metabolism and regulating adhesion and motility of respiratory epithelial cells. Res Commun Mol Pathol Pharmacol 97: 243-262.

11. Wessler I, Kirkpatrick CJ, Racke K (1998): Non-neuronal acetylcholine, a locally acting molecule, widely distributed in biological systems: expression and function in humans. Pharmacol Ther 77: 59-79.

12. Improgo MR, Soll LG, Tapper AR, et al. (2013): Nicotinic acetylcholine receptors mediate lung cancer growth. Front Physiol 4: 251.

13. Cooke JP, Ghebremariam YT (2008): Endothelial Nicotinic Acetylcholine Receptors and Angiogenesis. Trends Cardiovasc Med 18: 247-253.

14. de Jonge WJ, Ulloa L (2007): The alpha7 nicotinic acetylcholine receptor as a pharmacologicaltarget for inflammation. $\mathrm{Br}$ J Pharmacol 151: 915-929.

15. Schirmer SU, Eckhardt I, Lau H, et al. (2011): The cholinergic system in rat testis is of non-neuronal origin. Reproduction 142: 157-166.

16. Davis TJ, de Fiebre CM (2006): Alcohol's actions on neuronal nicotinic acetylcholine receptors. Alcohol Res Health 29: $179-185$.

17. Reardon C, Duncan GS, Brüstle A, et al. Lymphocyte-derived ACh regulates local innate but not adaptive immunity. Proc Natl Acad Sci U S A 110: 1410-1415.

18. Matteoli G, Boeckxstaens GE (2013): The vagal innervation of the gut and immune homeostasis. Gut 62: 1214-1222.

19. Sato KZ, Fujii T, Watanabe Y, et al. (1999): Diversity of mRNA expression for muscarinic acetylcholine receptor subtypes and neuronal nicotinic acetylcholine receptor subunits in human mononuclear leukocytes and leukemic cell lines. Neurosci Lett 266: 17-20.

20. Skok MV, Kalashnik EN, Koval LN, et al. (2003): Functional nicotinic acetylcholine receptors are expressed in B lymphocyte-derived cell lines. Mol Pharmacol 64: 885-889.

21. Sudheer PS, Hall JE, Donev R, et al. (2006): Nicotinic acetylcholine receptors on basophils and mast cells. Anaesthesia 61: 1170-1174.

22. Rosas-Ballina M, Ochani M, Parrish WR, et al. (2008): Splenic nerve is required for cholinergic antiinflammatory pathway control of TNF in endotoxemia. Proc Natl Acad Sci U S A 105: 11008-11013.

23. Rosas-Ballina M, Olofsson PS, Ochani M, et al. (2011): Acetylcholine-Synthesizing T Cells Relay Neural Signals in a Vagus Nerve Circuit. Science 334: 98-101. 
24. Olofsson PS, Katz DA, Rosas-Ballina M, et al. (2012): $\alpha 7$ nicotinic acetylcholine receptor $(\alpha 7 \mathrm{nAChR})$ expression in bone marrow-derived non-T cells is required for the inflammatory reflex. Mol Med 18: 539-543.

25. Parrish WR, Rosas-Ballina M, Gallowitsch-Puerta M, et al. (2008): Modulation of TNF release by choline requires alpha7 subunit nicotinic acetylcholine receptor mediated signaling. Mol Med 14: 567-574.

26. Sun F, Jin K, Uteshev VV (2013): A type-II positive allosteric modulator of $\alpha 7 \mathrm{nAChRs}$ reduces brain injury and improves neurological function after focal cerebral ischemia in rats. PLoS One 8: e73581.

27. Freitas K, Carroll FI, Damaj MI (2013): The antinociceptive effects of nicotinic receptors $\alpha 7$-positive allosteric modulators in murine acute and tonic pain models. J Pharmacol Exp Ther 344: 264-275.

28. Wang H, Yu M, Ochani M, et al. (2003): Nicotinic acetylcholine receptor $\_7$ subunit is an essential regulator of inflammation. Nature 421: 384-388.

29. Borovikova LV, Ivanova S, Zhang M, et al. (2000): Vagus nerve stimulation attenuates the systemic inflammatory response to endotoxin. Nature 405: 458-462.

30. Rosas-Ballina M, Goldstein RS, Gallowitsch-Puerta M, et al. (2009): The selective alpha7 agonist GTS-21 attenuates cytokine production in human whole blood and human monocytes activated by ligands for TLR2, TLR3, TLR4, TLR9, and RAGE. Mol Med 15: 195-202.

31. Shytle RD, Mori T, Townsend K (2004): Cholinergic modulation of microglial activation by alpha 7 nicotinic receptors. J Neurochem 89: 337-343.

32. Kawashima K, Fujii T (2000): Extraneuronal cholinergic system in lymphocytes. Pharmacol Ther 86: 29-48.

33. Kawashima K, Fujii T (2003): The lymphocytic cholinergic system and its contribution to the regulation of immune activity. Life Sci 74: 675-696.

34. Kawashima K, Fujii T (2004): Expression of non-neuronal acetylcholine in lymphocytes and its contribution to the regulation of immune function. Front Biosci 9: 2063-2685.

35. Fujii T, Tsuchiya T, Yamada S, et al. (1996): Localization and synthesis of acetylcholine in human leukemic $\mathrm{T}$ cell lines. J Neurosci Res 44: 66-72.

36. Wang DW, Zhou RB, Yao YM, et al. (2010): Stimulation of $\alpha 7$ nicotinic acetylcholine receptor by nicotine increases suppressive capacity of naturally occurring CD4+CD25+ regulatory $\mathrm{T}$ cells in mice in vitro. $\mathrm{J}$ Pharmacol Exp Ther 335: 553-561.

37. Nordman JC, Muldoon P, Clark S, et al. (2014): The $\alpha 4$ nicotinic receptor promotes $\mathrm{CD} 4+\mathrm{T}$-cell proliferation and a helper T-cell immune response. Mol Pharmacol 85: 50-61.

38. Nouri-Shirazi M, Tinajero R, Guinet E (2007): Nicotine alters the biological activities of developing mouse bone marrow-derived dendritic cells (Dcs). Immunol Lett 109: 155-164.

39. Vassallo R, Tamada K, Lau JS, (2005): Cigarette smoke extract suppresses human dendritic cell function leading to preferential induction of Th-2 priming. J Immunol 175: 26842691.

40. Nouri-Shirazi M, Guinet E (2012): Exposure to nicotine adversely affects the dendritic cell system and compromises host response to vaccination. J Immunol 188: 2359-2370.

41. Radosa J, Dyck W, Goerdt S, et al. (2011): The cholinergic system in guttate psoriasis with special reference to mast cells. Exp Dermatol 20: 677-679.
42. Mishra NC, Rir-Sima-Ah J, Boyd RT, et al. (2010): Nicotine inhibits fc $\phi$ RI-induced cysteinyl leukotrienes and cytokine production without affecting mast cell degranulation through alpha7/ alpha9/alpha10-nicotinic receptors. J Immunol 185: 588-596.

43. Kageyama-Yahara N, Suehiro Y, Yamamoto T, et al. (2009): IgE-induced degranulation of mucosal mast cells is negatively regulated via nicotinic acetylcholine receptors. Biochem Biophys Res Commun 377: 321-325.

44. Huston JM, Rosas-Ballina M, Xue X, et al. (2009): Cholinergic neural signals to the spleen down-regulate leukocyte trafficking via CD11b. J Immunol 183: 552-559.

45. Gilboa-Geffen A, Lacoste PP, Soreq L, et al. (2007): The thymic theme of acetylcholinesterase splice variants in myasthenia gravis. Blood 109: 4383-4391.

46. Gilboa-Geffen A, Wolf Y, Hanin G, et al. (2011): Activation of the alternative NFKB pathway improves disease symptoms in a model of Sjogren's syndrome. PLoS One 6: e28727.

47. Ofek K, Krabbe KS, Evron T, et al. (2007): Cholinergic status modulations in human volunteers under acute inflammation. J Mol Med (Berl) 85: 1239-1251.

48. Brenner T, Hamra-Amitay Y, Evron T, et al. (2003): The role of readthrough acetylcholinesterase in the pathophysiology of myasthenia gravis. FASEB J 17: 214-222.

49. Nadorp B, Soreq H (2014): Predicted overlapping microRNA regulators of acetylcholine packaging and degradation in neuroinflammation-related disorders. Front Mol Neurosci 7: 9, doi: 10.3389/fnmol.2014.00009. eCollection 2014.

50. Perry C, Pick M, Podoly E, et al. (2007): Acetylcholinesterase/C terminal binding protein interactions modify Ikaros functions, causing T lymphopenia. Leukemia 21: 1472-1480.

51. Couturier S, Bertrand D, Matter JM, et al. (1990): A neuronal nicotinic acetylcholine receptor subunit (alpha7) is developmentally regulated and forms a homooligomeric channel blocked by alpha-BTX. Neuron 5: 847-856.

52. Smedlund K, Tano JY, Margiotta J, et al. (2011): Evidence for operation of nicotinic and muscarinic acetylcholine receptor-dependent survival pathways in human coronary artery endothelial cells. J Cell Biochem 112: 1978-1984.

53. Schuller HM, Plummer HK 3rd, Jull BA (2003): Receptor-mediated effects of nicotine and its nitrosated derivative NNK on pulmonary neuroendocrine cells. Anat Rec A Discov Mol Cell Evol Biol 270: 51-58.

54. Jull BA, Plummer HK 3rd, Schuller HM (2001): Nicotinic receptor-mediated activation by the tobacco-specific nitrosamine NNK of a Raf-1/MAP kinase pathway, resulting in phosphorylation of c-myc in human small cell lung carcinoma cells and pulmonary neuroendocrine cells. J Cancer Res Clin Oncol 127: 707-717.

55. Paulo JA, Brucker WJ, Hawrot E (2009): Proteomic analysis of an $\alpha 7$ nicotinic acetylcholine receptor interactome. J Proteome Res 8: 1849-1858.

56. Marrero MB, Bencherif M (2009): Convergence of alpha 7 nicotinic acetylcholine receptor-activated pathways for anti-apoptosis and anti-inflammation: central role for JAK2 activation of STAT3 and NF-kappaB. Brain Res 1256: 1-7.

57. Tsurutani J, Castillo SS, Brognard J, et al. (2005): Tobacco components stimulate Akt-dependent proliferation and $\mathrm{NF \kappa B}$ dependent survival in lung cancer cells. Carcinogenesis 26: 1182-1195.

58. de Jonge WJ, van der Zanden EP, The FO, et al. (2005): Stimulation of the vagus nerve attenuates macrophage activation by activating the Jak2-STAT3 signaling pathway. Nat Immunol 6: 844-851. 
59. Chernyavsky AI, Arredondo J, Karlsson E, et al. (2005): The Ras/Raf-1/MEK1/ERK signaling pathway coupled to integrin expression mediates cholinergic regulation of keratinocyte directional migration. J Biol Chem 280: 39220-39228.

60. Trombino S, Cesario A, Margaritora S, et al. (2004): $\alpha 7$-nicotinic acetylcholine receptors affect growth regulation of human mesothelioma cells: role of mitogen-activated protein kinase pathway. Cancer Res 64: 135-145.

61. Paleari L, Catassi A, Ciarlo M, et al. (2008): Role of alpha7-nicotinic acetylcholine receptor in human non-small cell lung cancer proliferation. Cell Prolif 41: 936-959.

62. Wang H, Liao H, Ochani M, et al. (2004): Cholinergic agonists inhibit HMGB1 release and improve survival in experimental sepsis. Nat Med 10: 1216-1221.

63. Terrando N, Eriksson LI, Ryu JK, et al. (2011): Resolving postoperative neuroinflammation and cognitive decline. Ann Neurol 70: 986-995.

64. Waldburger JM, Boyle DL, Pavlov VA, et al. (2008): Acetylcholine regulation of synoviocyte cytokine expression by the alpha7 nicotinic receptor. Arthritis Rheum 58: 3439-3449.

65. Al-Wadei MH, Al-Wadei HA, Schuller HM (2012): Pancreatic cancer cells and normal pancreatic duct epithelial cells express an autocrine catecholamine loop that is activated by nicotinic acetylcholine receptors $\alpha 3, \alpha 5$, and $\alpha 7$. Mol Cancer Res 10: 239-249.

66. Nakamura S, Saitoh M, Yamazaki M, et al. (2010): Nicotine induces upregulated expression of beta defensin-2 via the p38MAPK pathway in the HaCaT human keratinocyte cell line. Med Mol Morphol 43: 204-210.

67. Li Q, Zhou XD, Kolosov VP, et al. (2011): Nicotine reduces TNF- $\alpha$ expression through a $\alpha 7 \mathrm{nAChR/MyD88/NF- \kappa B}$ pathway in HBE16 airway epithelial cells. Cell Physiol Biochem 27: 605-612.

68. Carlisle DL, Hopkins TM, Gaither-Davis A, et al. (2004): Nicotine signals through muscle-type and neuronal nicotinic acetylcholine receptors in both human bronchial epithelial cells and airway fibroblasts. Respir Res 5: 27, doi: 10.1186/1465-9921-5-27.

69. West KA, Brognard J, Clark AS, et al. (2003): Rapid Akt activation by nicotine and a tobacco carcinogen modulates the phenotype of normal human airway epithelial cells. J Clin Invest 111: 81-90.

70. Novak J, Escobedo-Morse A, Kelley K, et al. (2000): Nicotine effects on proliferation and the bombesin-like peptide autocrine system in human small cell lung carcinoma SHP77 cells in culture. Lung Cancer 29: 1-10.

71. Lawlor MA, Alessi DR (2001): PKB/Akt: a key mediator of cell proliferation, survival and insulin responses? J Cell Sci 114: 2903-2910.

72. Xin M, Deng X (2005): Nicotine inactivation of the proapoptotic function of Bax through phosphorylation. J Biol Chem 280: 10781-10789.

73. Scheid MP, Woodgett JR (2001): Pkb/akt: functional insights from genetic models. Nat Rev Mol Cell Biol 2: 760-768.

74. Kihara T, Shimohama S, Sawada H, et al. (2001): Alpha 7 nicotinic receptor transduces signals to phosphatidylinositol 3-kinase to block A beta-amyloid-induced neurotoxicity. J Biol Chem 276: 13541-13546.

75. Carlisle DL, Liu X, Hopkins TM, et al. (2007): Nicotine activates cell-signaling pathways through muscle-type and neuronal nicotinic acetylcholine receptors in non-small cell lung cancer cells. Pulm Pharmacol Ther 20: 629-641.
76. Ueno H, Pradhan S, Schlessel D, et al. (2006): Nicotine enhances human vascular endothelial cell expression of ICAM1 and VCAM-1 via protein kinase C, p38 mitogen-activated protein kinase, NF-kappaB, and AP-1. Cardiovase Toxicol 6: 39-50.

77. Chatterjee PK, Al-Abed Y, Sherry B, et al. (2009): Cholinergic agonists regulate JAK2/STAT3 signaling to suppress endothelial cell activation. Am J Physiol Cell Physiol 297: C1294-C12306.

78. Saeed RW, Varma S, Peng-Nemeroff T, et al. (2005): Cholinergic stimulation blocks endothelial cell activation and leukocyte recruitment during inflammation. J Exp Med 201: 1113-1123.

79. Chen RJ, Ho YS, Guo HR, et al. (2008): Rapid activation of Stat 3 and ERK1/2 by nicotine modulates cell proliferation in human bladder cancer cells. Toxicol Sci 104: 283-293.

80. Chen RJ, Ho YS, Guo HR, et al. (2010): Long-term nicotine exposure-induced chemoresistance is mediated by activation of Stat 3 and downregulation of ERK1/2 via nAChR and beta-adrenoceptors in human bladder cancer cells. Toxicol Sci 115: 118-130.

81. Zeidler R, Albermann K, Lang S (2007): Nicotine and apoptosis. Apoptosis 12: 1927-1943.

82. Jin Z, Gao F, Flagg T, et al. (2004): Nicotine induces multisite phosphorylation of Bad in association with suppression of apoptosis. J Biol Chem 279: 23837-23844. 